\title{
ENTREVISTA com Ana Claudia de Oliveira
}

por Sandra Regina Ramalho e Oliveira

1. Esta edição da Palíndromo, a de número 10, é consagrada ao Ensino de Arte, e seu tema é Interações entre Ensino de Arte e Semiótica. Como se pode perceber, o objetivo é aproximar a semiótica dos professores de arte. Se você pudesse indicar apenas três artigos para um professor de arte leigo em semiótica iniciar estudos nessa vertente teórico-metodológica, quais os títulos e autores você recomendaria?

Ensinar está entre as práticas de vida de maior relevo e, em nosso país, pode ser considerada fundamental na configuração de um novo amanhã em razão do teor transformacional de uma população que realmente é iniciada nos processos de ensino e aprendizagem. Em especial, construir um mundo novo com sujeitos comprometidos com os seus destinos tem participação especial do Ensino de Arte, que vai além do conhecimento de técnicas que garantem a codificação, a decodificão e a reprodução. Muito mais do que desenvolver essas habilidades, o ensino dos valores estéticos exerce a força de liberar o sujeito aprendiz das amarras do preestabelecido, fazendo-o descobrir a força da autodestinação que Ihe propicia um agir por si mesmo. Esses valores estéticos são os únicos que carregam uma força capaz de provocar desestruturações e revisões nos estados dos que os experienciam. Daí a prática de ensino da arte carregar uma condição de libertar o sujeito da destinação do outro e de desenvolver nele habilidades próprias que the permitam encontrar por si os rumos de seu viver. São rumos liberadores oriundos do desfrutar o que se apresenta nos encontros de coisas, objetos, outros sujeitos, em circunstâncias que são vividas e desabrocham com o vislumbrar os sentidos do sentir.

Assim, uma outra aresta do sentido, a sensível, cabe ser colocada em relação à da razão. Complementares e intercomunicantes, essas atuam formando a modalidade cognitiva que envolve a partilha entre inteligível e sensível com passagens abertas entre uma e outra. $O$ trânsito interpólos decorre dos tipos de experiência da construção do sentido, e esses arranjos múltiplos concedem autonomia ao sujeito apto a recorrer tanto a um quanto a outro nos processamentos significantes. 


\section{Qual é a importância desta autodestinação?}

Primeiramente, é o sujeito tornar-se senhor de sua aprendizagem com decisões próprias, ou seja, não mais ser só levado pelo destinador que comanda as operações de ensino, nem somente pelo destinador manipulador com o seu fazer direcionado, nem simplesmente aceitar os designos do acaso que the sucedem e resultam no aprender, mas também como um sujeito que sente o sabor do conhecimento, relaciona o que aprende com o seu estar no mundo e vai descobrindo o saber e descobrindo-se, pelo aproximar-se do conhecimento. O sujeito se põe em relação ao que aprende, sentindo o seu desenvolver-se e sendo por esse animado num interagir entre iguais. Essas condições variadas de processamento do sentido polarizadas em quatro mecanismos articulados que formam um sistema complexo de regimes de interação e de sentido foram teorizadas por Eric Landowski (Les intéractions risquées, PULIN, 2005. Trad. esp. Interaccionnes ariesgadas. Lima, Fondo Editorial de la Universidad de Lima, 2009). Enquanto quatro tipos de procedimentos esses mantêm articulação entre si montando distintos encadeamentos que cabe aos estudiosos observarem as dinâmicas no ensino aprendizagem. O sujeito depreende as suas condições de poder e saber encontrar meios para captar o sentido, assim como com as suas possibilidades, nos seus encontros, processa o sentido descobrindo-se nos caminhos. Todas essas partidas a jogar estão voltadas à construção do sentido um fazer que define o homem na sua incessante procura existencial. Essas são buscas semióticas, que se colocam nas empreitadas várias do sujeito que constrói os sentidos quer seja de uma obra de arte, de uma paisagem, de um fato do dia a dia, quer de um ponto dado pelo professor em sala de aula. E elas se desenrolam complexamente tanto orientadas pelos programas traçados para ser seguidos com passos préfixados quanto motivadas por alvos intencionais que animam a perseguir e persistir na trilha para alcançá-las, quanto pelo farejar caminhos pelos sentidos que fazem sentir a rota, tornando o sujeito um descobridor em ato, e, ainda, também pelo acatar desígnios do mundo nas ocorrências que ocorrem. Assim, esses tipos de processamento do sentido operam por mecanismos diversificados de interação e, inclusive, o sujeito desenvolve no seu existir suas preferências por proceder de um jeito ou de outro reiterações que vão caracterizar sua presença ao mundo com abertura ou fechamento, assim como como gradualidades entre essas posições extremas. A interação propicia então a construção dos tipos de conhecimento.

Considero muito importante levarmos adiante essas correlação entre interação e sentido 
na área do ensino, aí incluso o da arte. Na esteira das contribuições de Eric Landowski, a teoria semiótica é tomada enquanto uma teoria do sentido como inter-ação entre um sujeito e outro sujeito, quer esse seja uma coisa, um objeto, uma pessoa. Antes de tudo o mais são nas interações que o sujeito apreende e aprende a construir os sentidos, daí uma das relevâncias de fazer semiótica para poder ter com o seu método mais eficácia nos tipos de construção do sentido - um fazer que ativa o crescimento pessoal e também o coletivo na medida em que, ao se desenrolar as atividades, essas mesmas são transformadoras do sujeito.

Penso o ensino da semiótica enquanto uma reflexão sobre os sentidos da vida, pensados a partir dos modos de presença do sujeito ao mundo. Uma atividade interpretativa que tem por método de descrição e análise o "percurso gerativo do sentido" concebido em três níveis operatórios entre si, postulados por Greimas. Com uma gramática narrativa mais complexificada pelo complementação do "regime de união" (Landowski, "Além e aquém da manipulação, a presença contagiosa", in Documentos de Estudo do CPS n.4. São Paulo, Editora CPS, 2004), ao regime de junção, largamente definido e testado, os tipos de relações entre sujeito e objeto, sujeito e sujeito são estudados, assim como a organização semântica dessas narrativas. Arranjadas pelas escolhas do criador em função de um público, as narrativas que produzimos mostram os modos de se colocar no mundo. Podemos, então, pensar a teoria semiótica enquanto mecanismos de descrição e análise das narrativas da vida, destacando entre essas a da própria aprendizagem na escola, mas também fora dela. O mais relevante é que as narrativas escolhidas para serem estudadas estejam mescladas com as dos modus operandi do próprio ensino, que é vivido então enquanto uma prática de vida. $O$ ensino da semiótica estaria voltado para a busca do sentido dessas narrativas do sujeito na complexidade do seu existir. A exploração da arte é fundamental, pois, no seu universo criativo, ela presentifica em buscas várias procuras os modos e meios de existir. Cabe ao educador mostrar os caminhos da busca de sentido do artista e fazer desses uma reflexão para a vida. Cabe ainda desenvolver a aquisição dos códigos para que cada sujeito tenha habilidades de processá-los e dispor de mais formas de expressão. Penso a teoria semiótica como um arcabouço de procedimentos para entender os mecanismos do sentido da vida e do ensino. Essa dimensão não justificaria a aquisição da teoria? Não acha que tem um lugar para a teoria semiótica no ensino da arte?

Já fui citando alguns títulos que podem instigar a leitura dos interessados ao desenrolar 
as minhas reflexões sobre o tema deste número 10 de Palíndromo: Interações entre Ensino de Arte e Semiótica. A seguir, darei destaque a outros títulos de relevo e comentarei as razões de minhas escolhas.

Da Imperfeição (1987. Trad. port. São Paulo, Hacker, 2002), última obra individual de Algirdas Julien Greimas, em que o autor propõe aos semioticistas uma reflexão sobre a problemática do ser e do parecer, ou seja, dos modos de existência. O seu leitor, um parceiro iniciado, o semiotista, mas também qualquer leitor que busque o sentido da imperfeição, encontra no livro, em prosseguimento à edificação semiótica erigida, um projetar de sua continuidade. Entre um prefácio e um posfácio, Greimas considera em duas partes separadas as condições de ocorrência do evento estético mostrando que esse tem uma organização narrativa que permite ser analisável pelos postulados da gramática narrativa. A postulação do valor da estética das organizações semióticas é desenvolvido enquanto um tipo de ação que a componente estética, presente em toda e qualquer manifestação de linguagens, produz no viver humano. Na primeira das partes, o autor escolhe cinco fragmentos literários nos quais mostra a experiência estética em seus modos de ocorrência a partir do conclamar apreensões que articulam distintamente as ordens sensoriais. O criador da semiótica indica assim o processar estésico do corpo todo que sente os distintos modos de irrupção do estético e é por esse afetado. Um "acidente inesperado", a ocorrência estética descontinua o contínuo que acaba tornando-se uma sequência automatizada que amortiza o seu semantismo e produz um excedente de sentido que abala o sujeito. De irrupção brusca, esse acidente suspende os marcadores situacionais de tempo e espaço que situam o sujeito e seu viver, e ele experimenta um excesso de sentido que o lança aos ares e desestabiliza as suas certezas e seus valores. $\mathrm{Na}$ descrição de Greimas, de um estado de continuidade alça-se à polaridade oposta, a descontinuidade, sem passagens do sujeito pelo pólo subcontrário, que é justamente o ponto que Landowski propõe uma revisão, uma vez que toda posição de uma oposição de base só é ultrapassada pela trajetória obrigatória que passa pelo termo subcontrário. Desmembrando o acidente conforme caracterizado por Greimas, Landowski propõe que ele se reparta em dois procedimentos que mantêm entre eles uma relação implicativa, ou seja, um deles, que o autor chamou de procedimento de ajuste (o procedimento da interação entre dois sujeitos que se sentem sentindo o sentido que produz uma descoberta em reciprocidade), está em relação de contrariedade com o da continuidade, e ele opera o trânsito para o procedimento do acaso (o 
procedimento de interação em que se chocam dois projéteis temáticos imprevisivamente, tirando o sujeito de seu chão). A revisão não é sem consequências e foi dessa depreensão e reformulação conceitual de base que Landowski chegou a complexificar o modelo de análise da gramática narrativa. Alargado o arcabouço semiótico, as descrições e análises passaram a melhor dar conta da dinâmica do sentido.

Ainda em Da imperfeição, Greimas desenvolve a última viga de sua edificação do percurso gerativo do sentido, na semântica discursiva, a figuratividade que define como aquela que faz entrever o sentido. Fruto da operação de tradução dos mundos em linguagens que articulam um plano da expressão ao plano do conteúdo, esse é um mecanismo por meio do qual um sujeito empreende escolhas de elementos nos códigos que socialmente dispõe e com o seu arranjo plástico e semântico em correlação organiza a manifestação de algo do mundo em uma configuração de linguagem. Essas escolhas figurativas do enunciador carregam não só os seus modos de interação com o mundo, mas também os de interação com os sistemas e as constantes de seu usos vão caracterizar suas marcas pessoais que delineam o seu estilo. Em cada configuração, algo significa, e a nossa tarefa enquanto semioticista é procurar compreender como essa significa e o que ela significa. No encontro com esses objetos construídos, o sujeito experimenta e vive o sentido plasmado nas escolhas uma vivência que o habilita a poder e saber propor a outros experiências a viver. Assim, as narrativas não só contam experiências, mas também as propõem a outros que as vivem.

Esse modos de sentir, a estesia, tem ocorrências diferenciadas decorrentes de como as impressões sensíveis são capturadas e afetam o sujeito, desencadeando experiências significantes decorrentes da plástica e do ritmo da narrativa estética. Do acidente estético irrompe um excedente de sentido que se esvai no decurso de sua ação, o que reposiciona o homem no estado de espera do inesperado. Nos ciclos dessa narratividade sem fim que parte do estado de espera desemantizada, à transformação semantizadora mas que, como tudo se esgota esvaindo, fazendo o sujeito a, de novo, retornar ao estado desemantizado.

Em uma inversão do processamento dessa dinâmica narrativa que subjaz às escolhas literárias, na segunda parte de Da imperfeição, os êxtases arrebatadores são diluídos em pequenas partículas que podem vir à tona enquanto formulação significante que atua a partir dos arranjos dos objetos que entornam o sujeito com a finalidade de lhes mostrar o sentido, pelo repetir dos ritos da cultura, pelo cultivo de hábitos. Esses são pois arranjos minimais com 
o que o sujeito tem ao seu alcance para usar em suas montagens. Pequenos atos que mostram que a estética recobre todos os tipos de arranjos inclusive os utilitários. Ao bel prazer do sujeito está pois a sua decisão de graduar, o semantismo do componente estésico que ele mesmo pode então liberar a dosagem de sua distribuição em seu viver de modo que a experiencia de frações de sentido mantenham ativados a significação de seu viver.

Duas proposições, "Fraturas" e "Escapatórias", fazem Da imperfeição um livro desafio que originou, no seio da teoria semiótica, uma série de novas explorações teóricas, da qual só exploramos a landowskiana. No quadro de todas elas é que a dimensão sensível da experiência do sujeito é incorporada às investigações semióticas como um operar sensível do sujeito para apreender o sentido. Do sobrevôo de Landowski sobre a estruturação mesma do pensamento de Greimas, resultam as teorizações de "Fronteiras do corpo" (Lisboa, Revista Comunicação e Linguagem, 1999) que postulam o corpo enquanto um operador sensível que apreende sentindo o "sentido sentido" (Postulação que Landoswski faz em português no artigo "Viagens às nascentes do sentido", in Ignácio Assis Silva, Corpo e sentido. A escuta do sensível. São Paulo, Unesp, 1996).

Na Revista Educação e Realidade organizada por Analice Dutra Pillar (n. 30(2). Porto Alegre, 2005), pode ser encontrado um outro capítulo fundamental de Landowski: "Por uma semiótica sensível" no qual define a plataforma conceitual para entender o mundo pela sensibilidade, quer se trate do sentir o fazer sentido de uma praça, uma catedral, um museu, um parque, o sujeito sensiente opera em ato, processando as qualidades estésicas do que sente.

De minha autoria, na mesma revista, o artigo "Visualidade, entre significação sensível e inteligível" faz uma apresentação dos constituintes da visualidade e como tratá-la a partir da estrutura comunicacional imanente à manifestação. Os arranjos das relações interativas entre o enunciador e o enunciatário assumem formas de contrato ou de contato, em que inteligível e sensível interveem na montagem da organização do sentido.

Ainda um livro fundante da análise semiótica do plano da expressão das manifestações da arte é Semiótica plástica (São Paulo, Hacker-CPS Editora, 2004), no qual o capítulo de minha autoria "As semioses pictóricas" fornece os mecanismos de descrição e interpretação da arte defendendo que a semiótica como método fornece os meios de apreciação da arte, o que destaco como uma aproximação tanto estética quanto estésica. 
Das teses publicadas que orientei, a de Anamelia Bueno Buoro, com o título Olhos que pintam: a leitura da imagem e o ensino da arte (São Paulo, Cortez, 2002) faz uma interpretação das histórias da arte, as de Gombrich, Argan e Read, destacando a condição da arte e de seus arranjos de linguagens para produzir conhecimentos, cognição sobre os homens e os mundos que arquitetam. Como as teorias da arte são mostradas como interpretações da produção artística, a teoria semiótica oferece a elas os elementos para análise dos mecanismos de construção do sentido do próprio estar-no-mundo do sujeito artista ou teórico, a partir dos tipos de interação entre sujeito que apreende a obra, e essa, um outro sujeito, que se mostra por seus elementos articulados, para ser sentida e significada. A interação estrutura, portanto, o sentido e os modos de estudá-lo são realizados pela testagem do arcabouço teórico de Landowski com a proposição correlata entre "regimes de interação e de sentido", formulado enquanto um sistema de tipos de construção do sentido a partir dos tipos de interação.

Destaco ainda mais duas teses que orientei e foram publicadas em livros que divulgam os mecanismos da produção de sentido de objetos significantes. A de Sandra Ramalho e Oliveira "Leitura de imagens para a educação" (1998) traz uma variedade de objetos para tratálos enquanto visualidades passíveis de leitura e a de Moema Martins Rebouças "O discurso modernista na pintura" tem o contributo de especificar os contratos de veridicção e de fidúcia em ação na obra de arte, de modo a promover a compreensão de seus procedimentos.

Atuando na Pós-graduação em Comunicação e Semiótica da PUC-SP, desde 1990, vou completar em 2014 uma centena de teses e dissertações orientadas e defendidas em variados campos do saber: da arte, da performance, da visualidade, das mídias, da internet, do consumo, da moda, da roupa. Todas elas estão disponíveis on line na biblioteca da PUC-SP e tem como proposição que o componente estético é partícipe de todo e qualquer tipo de manifestação.

A teoria semiótica como concebeu Greimas é ancilar das demais disciplinas, e essas pesquisas mostram bem esse alcance interpretativo da disciplina.

2. Os primeiros títulos de livros de sua autoria, pela Editora Perspectiva, quais sejam, "Neolítico, Arte Moderna" e "Fala Gestual", são de um período no qual sua produção tinha como sustentação a Semiótica Peirceana. Como se deu a transição do seu 


\section{pensamento para a Semiótica Discursiva e quais as suas motivações?}

As teorias semióticas são várias, e cada uma tem um arcabouço próprio para pensar as traduções dos mundos em linguagens. A semiótica de Charles Sanders Peirce e a semiologia de Roland Barthes se autodenominam enquanto ciências dos signos. Por sua vez a semiótica de luri Lotman e a semiótica de Algirdras Julien Greimas definem-se mais como disciplinas dos processos modelizantes e da significação, atuando por meio de relações aquém e além dos signos.

Essas quatro vertentes fizeram escolas importantes, e uma das raras pós-graduações que abrigam o conjunto dessas teorias no mundo está sediada na Pontifícia Universidade Católica de São Paulo, a Pós-graduação em Comunicação e Semiótica. Quando fiz minha formação graduada tive ensinamentos da gramática narrativa ou estrutural de Greimas voltada aos estudos literários, igualmente estudei as postulações de Roland Jackobson que repercurtiam muito no Brasil, com o seu modelo comunicacional e as funções da linguagem. Porém, nos anos setenta, a PUC-SP estava centrada nos estudos peirceanos. Meus mestres eram oriundos desta formação difundida pela Pós-graduação em Teoria Literária, criada em 1970 por Lucrécia D'Aléssio Ferrara com um corpo docente de grandes teóricos, poetas e tradutores como Haroldo de Campos, Décio Pignatari, Leila Perrone-Moises. Poucos anos e a equipe alargou a área de atuação da Teoria Literária para a da Comunicação. No mesmo ato adicionou em coordenação aditiva a abordagem teórica privilegiada que orientava as pesquisas e a Pós que se firmou a partir de 1974 como Pós-graduação em Comunicação e Semiótica, que perdura até os nossos dias. Aí se vão 40 anos na formação de doutores e mestres no país. Nessa Pós, cursei mestrado (1978 a 1981) e doutorado (1983 a 1988) e, desde 1990, ensino e realizo as minhas pesquisas.

Preocupei-me na pesquisa do mestrado: Neolítico e Arte Moderna (Perspectiva, 1985) com as estruturas que aproximam as revoluções neolítica da industrial e estudei as manifestações abstratas das criações de objetos da arte e utilitários. Esses objetos foram tratados enquanto apreensões e traduções de mundos com uma escritura em que o sujeito assume um distanciamento do circundante, voltando-se aos próprios elementos e às regras de processamento das linguagens. Um afastamento mostrado por uma configuração que evita a mímese uma vez que a sua preocupação é a de apreender o vigente, que está presente nas coisas, nos objetos, nas pessoas e nos sentimentos e apresenta-se assim diagramático. As 
descobertas da ciência como as das artes dão-se por vislumbramentos de possibilidades, que detectam os mecanismos de estruturação das ocorrências novas. O geometrismo e a sintaxe minimal de articulação de elementos basilares determinam o encontro de similaridades entre momentos de vida e estados d'alma que se apresentam tanto nas cestaria dos índios Tucanos do Brasil quanto na vertente do cubismo de Braque e Picasso na trilha abstracionista que se completaria no construtivismo de Mondrian. Uma redução de uso de elementos e regras de combinação que resultam não nas árvores com seus revestimentos de raiz, tronco, galhos, copa, mas nos esquemas que as estruturam e que deixam plasmado o fazer de linhas contínuas retas, paralelas, diagonais, ziguezagueadas, tortuosas e linhas descontínuas interrompidas em seu traçado de formação de círculos, semicírculos, quadriláteros, triângulos, entre outras figuras geométricas que são distribuídas na superfície biplanar. Na medida em que essa arquitetura nos faz visualizar um quadro do mundo feicionado pelos seus elementos constituintes em funcionamento, essa configuração envolve menos os sentidos para ser processada, requerendo uma visão mais racional que é denominada de abstrata.

Entendendo que esse modo de configuração é só um dos termos de um par complexo tem-se que a abstração está em oposição ao modo mimético ou figurativo. Esses dois processos distintivos foram conceituados por W. Worringer enquanto duas matrizes de representação do circundante, dos conceitos, das ideias e dos posicionamentos. Havia nesta conceituação de modos de estar no mundo pelos modos de condificá-lo um vislumbre de que a polaridade dualista só marcava períodos artísticos estanques e que diferentes tipos de trânsito entre essas formulações opositivas estavam presentes em outras periodicizações. Abstração e mimetismo estabeleciam dois modos de organização das linguagens, e um advia do rompimento dos modos de estar no mundo ou em sintonia ou em afastamento. Mas além desse radicalismo situam-se, na história da arte, períodos de articulação das formas opostas entre si e caracterizam modos que combinam esses dois processamentos distintos entre si. $O$ fato é que então me interessavam as condições pelas quais o abstrato e o mimético (ou orgânico) ressurgiam nas manifestações humanas e podiam inclusive ser contemporâneos dependendo das relações do sujeito com o circundante. O reiterar dessas duas constantes e de articulações entre elas comprovava que a adoção dos mesmos modos de expressão eram decorrentes de similares modos de presença do homem no meio ambiente. Modos de distanciamento ou de aproximação marcam um ir e vir entre a abstração e o mimético nas manifestações artísticas. 
Em Fala gestual (Perspectiva, 1992), a questão da tradução centrava-se entre a palavra dos Evangelhos nas narrativas da Última Ceia e as pinturas de diferentes períodos da história da arte: o Quatrocentro, o Renascimento, o Barroco, o Surrealismo. Cada época foi examinada pelos modos de expressão das narrativas dos quatro evangelhos e como as distintas escolhas dos meios para mostrar a cena em dada angulação configuram os pontos de vista. Cada tela resultante exibe uma concepção a partir da escolha de um ângulo da trama narrada, de valores de época, mas também daqueles do criador que são cravados na gestualidade dos corpos, nas suas posições e distribuição na espacialidade em que a ceia plasmada se desenrola. Efetivamente me interessavam NÃO É PLURAL? os modos como cada estilo significava uma visão axiológica pelas maneiras de compor a cena com a iluminação interior, exterior, ou intercomunicando dentro e fora, com o posicionar dos doze apóstolos em relação a Jesus Cristo, considerando que grupo formam em relação aos membros que ali estão e também ao contexto da passagem. Por si só as escolhas dos meios mostram como se traduzem as narrativas de palavras em narrativas pintadas. Um mesmo sistema como no caso o pictórico mostra os mecanismos de seu processo tradutório do arranjo verbal em função do artista, da época e dos valores que dão a ver os distintos modos de configuração. No compor e recompor, a caracterização de estilos de época, mas também de particularidades dos próprios criadores.

Essas duas investigações de fôlego desenvolveram análises dos modos de existência dos homens a partir dos tipos de relação com o circundante, quer esse seja o mundo físico, quer os das concepções, e as análises semióticas não se invalidam por ter sido realizada pelo arcabouço da semiótica peirceana. Absolutamente, não há razões para negar a minha sólida formação de base, pois ela me permitiu então depreender as categorias classificatórias constantes entre as relações entre manifestações sígnicas e as do mundo.

Sobretudo, como eram os processos de discursivização do sentido e não as classificações sígnicas que me instigavam, no término do doutorado me orientei rumo a uma outra vertente da semiótica. Nessas investigações de universais sintagmáticos que realizei sempre existiu uma aproximação com a antropologia estrutural de Claude Lévi-Straus e trilhei os pós-doutorados em busca de compreender nos processamentos dos arranjos de linguagens os tipos de interação do criador e daquele a quem a manifestação se destina.

Nos caminhos teóricos da continuidade de minhas investigações foi que me enveredei pela vertente mais social da semiótica, uma vez que eram as narrativas dos homens tomadas 
como explicativas de suas formas de vida, das visibidades que davam de si, do outro e do agrupamento social que me instigavam examinar nos encadeamentos dos enunciados de transformação e de estados, a narratividade. Encontrei mais na teoria das relações aquém e além dos signos condições para desenvolver o que eu já vinha investigando a propósito das traduções de mundos em arranjos de linguagens, e os conceitos de figuratividade e plasticidade, assim como o de enunciação ganharam força nas minhas abordagens discursivas. A opção de pós-doutorado em Paris resultou na iluminação dos mecanismos de visibilidade dos estabelecimentos comerciais e como se dá a circulação dos valores nas montras que fazem ver produtos em arranjos de gosto da marca, da loja, da população. Vitrinas, como acidentes estéticos da cotidianidade (Educ, 1997) condensa essa investigação realizada nas ruas da capital francesa, ruas da moda e dos modos de levar a vida.

Quando eu cheguei em Paris, no final de 1990, Greimas estava morando no interior da França e só vinha a capital para o seu Seminário de Semiótica na École des Hautes Études en Sciences Sociales (EHESS) que continuava mensalmente. Trabalhei de perto com Eric Landowski e, dos muitos conceitos que estão na sua visada sociossemiótica, recorri à noção de "simulacro" como a tradução modelar de arranjos figurativos dos mundos, regimes de visibilidade a partir dos jogos ópticos, estabelecimento de contratos veridictórios e fiduciários e, em especial, contratos enunciativos pelo arranjo de escolhas nos modos de figurativizar os temas no ato de discursivizar, ato que faz ser o sentido. Daí nasceu uma duradoura colaboração com Landowski, cuja obra pauta as minhas investigações e, juntos, produzimos uma série de estudos que estão publicados em coletâneas que registram etapas da pesquisa coletiva.

Como publicitária interessei-me pelas abordagens de como a linguagem verbal oral e a escrita e a visual na complexidade da fotografia, da gestualidade, da proxêmica, da tipografia, do design gráfico se articulavam na espacialidade do formato do impresso ou na temporalidade do audiovisual. Os modos sincréticos de arranjar as várias expressões levou-me aos estudos da semiótica sincrética e à abordagem de sua plástica à la Jean-Marie Floch, ou seja, pela estratégica única de enunciação que comanda os arranjos dos elementos das distintas linguagens articuladas. Seguir seu Atelier de Semiótica visual foi-me de grande valia, e anos de exploração dos procedimentos sincréticos levaram-me a estabelecer uma tipologia de modos de sincretizar ("A plástica da enunciação sincrética. Desenvolvimentos de semiótica sincrética," 
in Linguagens na comunicação, Estação das Letras e Cores e Editora do CPS, 2009).

Em paralelo aos estudos midiáticos, mantive o meu interesse pelas artes e, graças ao arcabouço da semiótica francesa, passei a dedicar-me ao tratamento dos processos interativos dessas manifestações abordadas como procedimentos da enunciação que instauram os modos de sentir os efeitos de sentido como apreensão e os modos relacionais de articular a construção do sentido. A apreensão e o reconhecimento da construção de sentido são assim duas operações que se imbrincam. Quanto mais a ação dos sentidos é exigida para sentir com os sentidos, mais atuante é a etapa de apreensão no processamento, quanto mais intervém no processo o reconhecimento dos elementos e de seu participar em sua estruturação, menos sensibilidade e mais decodificação segundo o aprendizado e o repertório do sujeito, que vão caracterizar a etapa da atribuição do sentido, que é chamada geralmente de leitura. Apreensão e reconhecimento são, assim, dois procedimentos da construção de sentido. Eles não só caracterizam o fazer humano, mas, talvez, seja essa atividade initerrupta também o seu ato maior de conferir sentidos ao mundo e a si mesmo.

3. E. Landowski e J. Fontanille fizeram parte da École de Paris, coordenada por A. J. Greimas. Hoje eles propõem postulações análogas, semelhantes, mas não idênticas. Como é difícil para os apenas iniciados identificar as diferenças, você poderia apontálas?

Landowski e Fontanille não fizeram parte como algo acabado da École de Paris, pois ainda hoje os dois integram a semiótica desenvolvida em torno das postulações de Greimas. Nas Ciências Humanas, não temos o costume de grupos de pesquisa em que o coordenador lança desafios para que, com ele, os colaboradores, e não seguidores, desenvolvam aspectos teóricos e metodológico de investigação. O que mais existe são grande teóricos e seguidores. Esse parece o traço diretivo mais marcante do mestre lituano na liderança dos que se agrupavam ao redor de suas postulações, o que não eram poucos. A semiótica atrai estudiosos do mundo todo enchendo os bancos dos Seminaire de Sémantique génerale, junto à Ecole des Hautes Études en Sciences Sociales (EHESS). Nos anos setenta, a disciplina podia ser considerada uma moda como as disciplinas dos demais criadores do Estruturalismo. Greimas soube indicar rumos para as suas proposições e determinar tarefas aos participantes, e os trabalhos preparados eram oportunamente debatidos no seu Seminaire, que assim pode ser 
considerado um grande palco de discussões e de testagens. A máxima mesma de um dos colaboradores, Jean-Marie Floch, era de que o arcabouço semiótico tem de ser posto à prova a cada análise, uma constante que fez os diferentes desenvolvimentos dos integrantes do grupo não se tornarem divergências, mas amplo campo de testagens e de comprovações que eram incorporadas. Assim é que o lexicólogo que Greimas era pôde constituir primeiro em parceria com Joseph Courtès o Dicionário de Semiótica I (Contexto, 2004) e em uma larga equipe o Dicionário de Semiótica II. Cada verbete dos conceitos-chave nesta obra chega a ter várias assinaturas de semioticistas, na medida em que o verbete agrupa na definição conceitual os distintos desenvolvimentos realizados pelos colaboradores.

Com uma liderança carismática, o projeto de uma semiótica estrutural foi construído coletivamente a partir de um conjunto conceitual coeso que pode ser acompanhado também para a apreensão dessa dinâmica nas publicações dos Documents e Bulletins do Groupe d'Etude Sémio-linguistique. Muitos desses trabalhos tornaram-se livros individuais, mas os periódicos constituem um rico material do desenrolar do modelo teórico que se firmou.

Landowski participou ativamente dessas publicações que formavam as Actes Sémiotiques, registros dos avanços que proporcionavam um elo efetivo da comunidade situada em vários países do mundo. Integrando o conselho editorial e assinando uma quantidade de prefácios para apresentar os temários e artigos publicados, Landowski permanece ainda na atualidade à frente do periódico reestruturado, que eletronicamente é posto na rede duas vezes ao ano. Fontanille garantiu na Université de Limoges que a revista, que passou a ser denominada Nouveaux Actes Sémiotiques, continuasse viva circulando impressa pela Editora Pulin e, depois, passasse a ser uma publicação eletrônica. Esse empreendimento de Fontanille não é de menor monta e deve ser bem ressaltado. Ter conseguido encontrar os meios para manter a periodicidade é fundamental para uma mídia, e isso se deu graças a Fontanille. Desde o ano 2013, com uma proposta diversificada nas línguas de publicação e com um corpo de pareceristas mais diversificado, a Revista eletrônica volta a ser nomeada tão somente Actes Sémiotiques, continuando a ser publicada com a editoria de Landowski e Fontanille. Vejo os dois semioticistas muito compromissados com a difusão dos avanços da teoria que se dá pelo mundo todo.

Mencionada essa atuação conjunta, eu poderia referir-me também aos bons laços de cordialidade que unem esses dois semioticistas em ações bastantes diversas. Enquanto 
Fontanille trabalhou muito para encontrar na França meios institucionais para abrigar o Seminário Internacional de Semiótica, Landowski não parou de viajar animando a teoria nos vários países que visitava sempre levando a visada de pesquisa que se debate em fóruns qualificados de discussão. Porém, preciso restringir a minha resposta.

Oriundos de campos diferentes em sua formação graduada, os dois estiveram juntos ao longo dos trabalhos do Groupe Sémio-linguistique. Landowski, ocupando-se dos modos de presença no social, na política, enquanto Fontanille, vindo das letras, teve na literatura seu campo de estudo. Mas é no fazer semiótica que a diferença maior entre os autores pode ser notada. O tratamento de objetos comuns que os ocupam, quer seja o discurso, quer seja a concepção e o papel do corpo tanto o do sujeito que sente quanto o do sujeito que faz o outro sujeito sentir, mostra um posicionamento radicalmente diferente. Ao considerar o encontro estésico entre dois sujeitos na interação, a tentativa de Landowski foi a de superar a dicotomia da visão dualista das lógicas da razão e da paixão, guiadas até então pelo modelo modal da gramática narrativa, modelo esse que foi mantido em Semiótica das paixões (1992), que Fontanille escreveu com Greimas. Os fundamentos da lógica da razão estão expressos em termos de dois regimes do que o autor denomina de "constelação da prudência" que mantém uma relação implicativa entre eles, e dois outros regimes da "constelação da aventura", com uma lógica outra, do risco e da sensibilidade, que foram propostos em Paissons sans nom (2004) e, como modelo completo, em Les intéractions risquées (2005) - e mantém entre eles a relação implicativa. O corpo que sente e faz sentir é um corpo sensível e aberto à imprevisibilidade e á descoberta de uma outra coisa. A integração do componente sensível fazse pelo conjunto de qualidades estésicas imanentes às coisas, aos objetos e aos seres que, em uma relação entre corpos, fazem o mundo percebido imprimir-se por seus efeitos de sentido à apreensão, interfere nos afetos e nas disposições patêmicas. Aos dispositivos actanciais e modais, as disponibilidades estésicas e as modulações que, formando sistema, articulam em Landowski inteligível e sensível para dar conta da inteligibilidade do sensível e da sensiblidade do inteligível no processo interativo de produção da significação. Distintamente a concepção de corpo de Fontanille mantém-se na oposição entre razão e sensibilidade, sem um terceiro mediador, o subcontrário mesmo que conflui nas arenas dos dois polos. Assim, a semiotização das paixões vai expor bem as diferenças.

Essa sua questão é muito complexa e exigiria um desenvolvimento comparativo bem 
mais aprofundado do que não posso dar conta neste curto espaço da resposta.

\section{Quem transita de um lado para o outro, ou seja, do campo das teorias semióticas para o da sua aplicação na Educação, percebe uma diferença abissal entre a densidade do aparato teórico- metodológico da Semiótica e sua aplicação nas escolas. $O$ que você teria a recomendar para aproximar a Semiótica da Educação?}

Não penso que a teoria semiótica seja concebida assim para ser aplicada do modo como vários termos da pergunta alinham. O conceito mesmo de "aplicação" me parece inadequado para uma disciplina que se ocupa do sentido. Diante de quaisquer fenômenos, no caso os da Educação, como tudo que é analisável, só pode ser estudado pelos modos como opera, pelos mecamismos de funcionamento e pelos de produção de efeitos de sentido. $O$ que requer a montagem de recortes no objeto de estudo que permitam chegar a partes significativas que reoperem o todo. O pesquisador tem aí desde o início demarcada a postura de não estudar de fora o objeto, mas ele assume ser parte integrante e participante da construção do que estuda. Assim, a experiencia investigativa é como uma prática de vida. Com esse conceber, a semiótica não consegue investigar a Educação enquanto uma amplitude genérica, pois isso torna o objeto de estudo muito difuso, e não permite ao semioticista apreender os contorno de sua especificidade. Fazem-se necessários muitos recortes para conseguir formar quadros de semiotização, por exemplo, por temas e figuras, pelas narrativas integrantes das práticas, por procedimentos de convencimento, de contratos que possam ser descritos em seus elementos constituíntes e modos de organização para, enquanto objetos demarcados, totalidades de sentido serem analisados e interpretados. A semiótica é um aparato de visada e entendimento do mundo que permite descrever, analisar e interpretar consistentemente pela metodologia do percurso gerativo do sentido as ocorrências significantes, entre elas, as práticas da educação. Entendido como uma sucessão de níveis, que mostra como se produz e se interpreta o sentido, a saber: as estruturas fundamentais, as estruturas narrativas e as estruturas discursivas - esse é um método de descrição e análise com reversibilidade entre os níveis, pois o que se levanta de um vai ter de ser homologado no outro, o que faz a semiótica ser um ato de testagem continuada em busca das estruturas particulares do processo de significação estudado.

Não emprego maiúsculas em minhas respostas, como existem nas questões propostas pela revista, pois em cada uma delas, por si só, destaca-se o nomeado. A postura do 
semioticista é a de um observador, mas também de um participante que, no papel de sujeito, estabelece interações como o outro sujeito. Que professor então não precisa tornar-se semioticista? Os modos como os sujeitos do processo de ensino e aprendizagem se mostram uns aos outros marcam os seus modos de presença ao mundo que interferem nos seus modos de interação. Esses modos de presença são captados e, na medida em que um sujeito é afetado ou não pelo saber, ele assim mostra-se ao outro. Cabe ao sujeito analista apreender e compreender esse processo de micro transformações que se somam umas às outras, não em uma conta de somatória certa, mas de processamentos individuais que desembocam na virada da aprendizagem. A sensibilidade do mestre e a do aprendiz interagem tanto quanto a racionalidade de ambos em uma gama de possibilidades de realização. Esse pôr-se em relação com o saber mediado pelo professor tem importantes etapas em que a aprendizagem é processada. Ainda acho que devemos dar mais atenção na escola aos processamentos sem hierarquias, aqueles em que o sujeito aprendiz se põe em pé de igualdade com o que ele estuda em um encontro entre iguais. A sensação desse estado aguça a disponibilidade para aprender na medida em que faz o aluno absorver por ele mesmo como tratar o conhecimento. Com esse modo de escuta do como se aprende é que brotam os indicativos do que lançar mão da teoria semiótica para iluminar mais e mais o ensino e a aprendizagem.

Nessa perspectiva, o universo da educação não difere do universo das mídas, das artes e tantos outros mais. Para a semiótica ser levada para a educação, como ela foi levada para outros domínios, ela necessita adentrar onde a educação se faz, para ser conhecida e estudada como um dos arcabouços teóricos e metodológicos ao alcance do professor para ele descrever, analisar e interpretar as manifestações do ensino escolar. Entender como essa teoria permite a análise das interações entre os sujeitos presentes na escola, entre os sujeitos e os ambientes escolares, entre os sujeitos e os materiais, entre os sujeitos e o contexto social. A semiótica precisa, pois, entrar na escola, nas salas de aula, nos livros didáticos e paradidáticos, no próprio interagir do espaço escolar e o de seu entorno, na relação pedagógica e tornar-se uma teoria praticada, como uma aposta de iluminação das práticas significantes e da sua produção de sentido.

A recomendação é descobrir o que a semiótica pode oferecer enquanto uma parceira para caminhar de mãos dadas com a educação. Acredito nessa caminhada conjunta: a semiótica servindo à educação. Greimas defendia a disciplina como ancilar das ciências 
humanas. Mas para isso é preciso a semiótica estar entre as teorias que figuram na grade de formação dos futuros professores. Temos, assim, de nos empenhar muito para isso se tornar realidade, não é?

\section{Analice Pillar e Moema Rebouças são pesquisadoras incansáveis na produção,} propagação e aplicação dos princípios da Semiótica Discursiva no nosso país. Como dar mais visibilidade à sua produção e de seus orientandos?

Pillar e Rebouças são ambas lideres de Grupos de pesquisa cadastrados no CPNq, e investigadoras atuantes na Área de Arte e associadas da ANPAP de longa data. As duas têm pós-doutorados recentes no exterior e penso que têm nucleações de pesquisa importantes com vários titulados que estão em exercício na educação da arte em seus estados. Talvez, elas pudessem estar interligando as suas equipes de pesquisa para levar a cabo um projeto temático nos moldes do que estamos desenvolvendo em São Paulo entre PUC-SP e UNESP no âmbito da comunicação social. As agências de fomento estão atuantes no país e seria preciso seguir os editais de financiamento para acompanhar as melhores oportunidades de fomento. Uma pesquisa colaborativa não nasce sem bases teórico-metodológicas e objetos comuns, e as duas pesquisadoras, além de preencherem esses quesitos têm condições de liderança para empreender essa tarefa conjunta. Vocês também têm essas condições aqui na UDESC. Todas as três são ligadas aos estudos pós graduados e poderiam estabelecer em uma parceria colaborativa interestadual.

Como investigadores em semiótica teriam de levantar o que têm feito cada um isoladamente em sua instituição de ensino e pesquisa, por exemplo, levantando as teses e dissertações que orientaram, os artigos e livros publicados, tudo isso com o propósito de encontrar os pontos em comum do que já vêm fazendo. É importante partir do concreto, do existente, uma vez que é de dada realidade que se descortina o sonho e imaginação do que se poderá realizar juntos. Se elas, ou se vocês com elas quiserem, poderiam pensar conjuntamente nas modalidades de ensino, inclusive de ensino à distância para preparar professores de arte ou promover aprofundamentos em especialização. Também caberia refletir sobre como está se dando o uso das mídias na educação. Essas são só algumas das tantas possibilidades mais que poderão mostrar o alcance da semiótica na área da educação. 
De um patamar de confluências do que já está solidificado na ação investigativa de cada grupo de pesquisa é que se poderá traçar compartilhadamente um projeto coletivo. As investigações, o trabalho e ainda os anseios de cada grupo precisam, então, ser postos em comum e só assim será possível descobrir em interação o melhor caminho a seguir para uma investigação coletiva.

Também esse modo de criar vínculos vai além das pessoas responsáveis na medida em que ele engaja de bolsistas de iniciação científica a pós-doutores. Trazer o graduando para os núcleos de investigação é muito importante e sua riqueza pode ser maior se o projeto abranger graduações diversas operando assim na transversalidade do sentido, na interdisciplinaridade. Com um fazer coletivo desta monta, não tem como não sensibilizar um ao outro. Vale o esforço se quiserem tentar.

Outra ação que poderia ser incrementada é a possibilidade que tem todo pesquisador: a de publicar as suas pesquisas em boas editoras que garantam a distribuição nacional e também visar traduções. Neste âmbito seria possível chegar a uma eleição de um temário comum aos grupos que orientasse desenvolvimentos em paralelos e que pudesse encaminhar para estudos comparativistas. Assim poderiam traçar projetos de publicação que fossem em periódicos e coletâneas. Talvez, esse seja o ponto estratégico mais imediato.

Vejo portanto muitos horizontes como possibilidades, mas é preciso que vocês decidam, e não é necessário absolutamente fazer algo em equipe sistematizada desde o início. Cabe uma caminhada inicial que invista nas descobertas. A situação que vivo no Centro de Pesquisas Sociossemióticas - CPS é muito coletivizada e a expus por achá-la muito construtiva. Por anos, Moema Rebouças tem levado ao debate em nossas reuniões de trabalho importantes semiotizações das práticas educacionais. No final de 2013 , inclusive propus que realizassemos um seminário para aprofundamento das práticas da educação.

O que realmente importa então é vocês continuarem atuantes como são e formando bem os pesquisadores em educação da arte. Isso não é pouco, ao contrário! E, sem dúvida, já é um ponto de interlocução e de colaboração. Continuar a participar das várias reuniões científicas da semiótica e da educação é um modo de continuar partilhando ideias e projetos. Temos de apostar nessa força de disseminação do trabalho de pesquisa e, sem um prazo marcado, o bom trabalho é reconhecido. 


\section{Depois de haver orientado diversas dissertações e teses que articulam Semiótica e Educação, mais especificamente, Semiótica e Ensino de Arte, o que você vislumbra como objeto de estudo ainda inexplorado nos espaços de entrelaçamentos entre Ensino das Artes Visuais e Semiótica?}

A prática pedagógica do ensino de artes tem sido ainda timidamente estudada. Anamélia Bueno Buoro, Moema Martins Rebouças e Lucimar Bello Franger fizeram um trabalho pioneiro junto à Fundação lochpe mas era mais no sentido de mostrar o alcance da interpretação semiótica das manifestações artísticas e propor modos de presença da imagem que favorecessem um contato maior com as obras de arte. Rebouças continuou essa linha de trabalho na Universidade Federal do Espírito Santo - UFES e o grupo do Centro de Pesquisas Sociossemióticas - CPS aí sediado, integrado ao Grupo de Pesquisas Processos Educativos da Arte - GEPEL, tem levado a semiótica para o espaço da escola que é pensado além dos materiais que entram na produção de sentido educacional e considera todo o espaço de interação institucional. Montagens da sala de aula e articulação entre elas, com montagens dos espaços dos que dirigem e coordenam as atividades, além dos imbricamentos entre as distintas espacialidades na temporalidade escolar de pátio, quadra poliesportiva e salas outras que a de aula normal, em todas essas espacialidades o foco se volta para a relação intersubjetiva dentro dos muros da escola com seus materiais em imbricamentos com as relações além muros. Todos esses ambientes são considerados como constituintes do sentido da escola e, neles, desenrolam-se papéis narrativos que atuam na transformação dos sujeitos, quer os que ensinam, quer os que aprendem. Essa interação complexa da escola envolve também o seu posicionar-se na cidade e como nela chegam os que a frequentam o que envolve as interações entre a escola e a cidade. Muitos dessas questões estão na reflexão registrada no livro $A$ cidade que mora em mim (2009)e também em teses orientadas na Pós de Educação da UFES que tanto pensaram a própria espacialidade como condições de aprendizagem, como também as várias mídias: jornais, revistas, televisão, celular e internet, redes sociais e os modos como essas são propostas em atividades escolares.

Outra frente é a de educação à distância que tem levado ensinamentos da semiótica a professores de zonas distantes. 
Também tenho seguido as repercussões do trabalho de Analice Dutra Pillar com a teoria semiótica na Pós-graduação em Educação da Universidade Federal do Rio Grande do Sul. Desenvolvendo semiotizações do olhar de educandos e professores, com um saber sensibilizador sobre os processamentos do sentido, tanto nos trabalhos com a arte quanto nos com a mídia.

Porém, refiro-me a algo mais que tange as próprias práticas da vida escolar que deveriam ser mais estudadas enquanto uma rede de sentidos que significa o estabelecimento de ensino, docentes e discentes, enfim, o contexto social. Esse estudo a mais envolveria um apropriar-se da vida escolar vivida, como uma experiência que visa realizar uma "operação" de ensino e aprendizagem, no modelo de Landowski, segundo um regime de programação, articulado ao "fazer fazer" com as estratégias intencionais de conduzir os ensinamentos, regime de manipulação, em relação ao "fazer sentir" o saber e o poder do saber se fazendo, assim como de sentir a própria vida escolar como descoberta significante do mundo, do outro, de si próprio, regime de ajustamento. Sem desconsiderar ainda tudo o que vier acontecer no imbricar desses regimes que, como acidentes que descontinuam o percurso, requerem espírito de inovação para aproveitar as situações com as oportunidades delas advindas, regime de acidente. Considerando que esses quatro regimes no sistema de funcionamento que engendram têm uma dinâmica ininterrupta de passagens figurando uma elipse, é possível vislumbrar que a teoria semiótica, enquanto interação que perspassa as instâncias da vida, produz patamares cognitivos para entender o processamento das situações escolares. Trabalhar com essas práticas tem importância capital uma vez que a escola atravessa a vida humana, e seu propósito maior é o de dar condições de existência aos sujeitos pelos seus modos de presença significantes que fazem ser e viver em condições favoráveis ética e esteticamente. 